\title{
ENFERMEDAD POLIQUÍSTICA DEL ADULTO EN RIÑÓN EN HERRADURA
}

\author{
R. FERRERO DORIA, F. MORENO PÉREZ, S. CALATRAVA GADEA, F. GARCÍA VÍCTOR, \\ M. GASSÓ MATOSES, E. DÍAZ CALLEJA
}

Servicio de Urología. Hospital Francesc Borja de Gandía. Gandía (Valencia).

Actas Urol Esp. 28 (3): 243-244, 2004

\section{RESUMEN}

ENFERMEDAD POLIQUÍSTICA DEL ADULTO EN RIÑÓN EN HERRADURA

Presentamos un caso poco común dentro de la práctica urológica habitual, consistente en la coincidencia en un mismo paciente de dos enfermedades renales congénitas asociadas: riñón poliquístico y riñón en herradura. Se describe la forma de presentación clínica, los métodos diagnósticos utilizados y el manejo terapéutico que se está realizando en este paciente.

PALABRAS CLAVE: Riñón. Riñón poliquístico. Riñón en herradura. Enfermedades renales congénitas.

\section{ABSTRACT}

ADULT POLYCISTIC KIDNEY IN HORSESHOE KIDNEY

A case report of kidney polycistic and horseshoe kidney coincidence in the same patient. They are two congenital associated renal diseases uncommon for urologists. The form of clinic presentation is described, the diagnostic methods used and the therapeutic management.

KEY WORDS: Kidney. Polycistic kidney. Horseshoe kidney. Kidney congenital disorders.

$\mathrm{E}^{\mathrm{i}}$ 1 riñón en herradura es una anormalidad renal poco frecuente consistente en la fusión de ambas unidades renales a través de su polo inferior en la línea media. Asímismo la incidencia de la enfermedad hereditaria poliquística del adulto es baja. Aportamos a la literatura un caso raro de asociación de ambas entidades.

\section{CASO CLÍNICO}

Paciente de 51 años de edad con antecedentes de ulcus péptico, hipertensión arterial (160/110) y como único antecedente urológico el de infecciones urinarias no complicadas en tres ocasiones. Remitido por su médico de Atención Primaria para estudio de estas infecciones. Refiere haber presentado clínica típica de cistitis aguda.
A la exploración abdomen blando sin globo vesical, sensación de masa abdominal, genitales externos normales, fosas lumbares normales y tacto rectal con hipertrofia prostática volumen II/IV, fibroelástica móvil, bien delimitada y sin nodulaciones.

Analítica de sangre: urea $50 \mathrm{mg} / \mathrm{dl}$, creatinina $1,97 \mathrm{mg} / \mathrm{dl}$ y PSA $2,3 \mathrm{ng} / \mathrm{ml}$. Niveles de sodio y potasio dentro de la normalidad.

Analítica de orina: 10-20 hematíes por campo.

El estudio urográfico muestra discretos cambios degenerativos en esqueleto axial. Ambos riñones de tamaño aumentado, con aproximación de los polos inferiores a la línea media y salida de ambas pelvis renales en anteroversión, típicos de riñón en herradura. Distorsión y estiramiento de los infundíbulos caliciales con muy discreta ectasia calicial, sugestivo de quistes múltiples 
tiples bilaterales. Uréteres permeables. Vejiga sin defectos de repleción con impronta prostática y mínimo residuo post-miccional.

Citología urinaria de micción espontánea negativa para células tumorales.

TAC abdominal (Fig. 1): riñones aumentados de tamaño, con incontables imágenes quísticas bilaterales y riñones unidos en la línea media a través de sus polos inferiores. Imágenes quísticas hepáticas.

El paciente tiene dos hijos: varón de 23 años y mujer de 12 años, siendo únicamente el varón el que en el estudio ecográfico presentaba quistes renales y hepáticos (Fig. 2).

En la actualidad, tres años desde el diagnóstico, el paciente está bajo control y seguimiento por el Servicio de Nefrología presentando niveles de creatinina de $3,48 \mathrm{mg} / \mathrm{ml}$ y de urea de $83 \mathrm{mg} / \mathrm{dl}$ $\mathrm{y}$ siguiendo un tratamiento con dieta de restricción proteica, hipotensores, alcalinizantes junto a calcitriol para su osteodistrofia renal. No se han repetido nuevos episodios de infección urinaria.

\section{DISCUSIÓN}

El riñón en herradura es una patología conocida en el ámbito urológico consistente en un defecto embriológico con fusión anormal de ambas unidades renales. La incidencia de este tipo de malformación varía según las publicaciones entre $1 / 400$ hasta $1 / 1800$ nacidos vivos ${ }^{1,4}$. Así mismo, la enfermedad poliquística del adulto, desorden de transmisión hereditaria autosómica dominante, tiene una incidencia que oscila entre $1 / 250$ y $1 / 5000 \operatorname{casos}^{2-4}$ y es considerada como una enfermedad sistémica por su asociación a aneurismas intracraneales, anomalías valvulares cardiacas, divertículos de colon ${ }^{1}$.

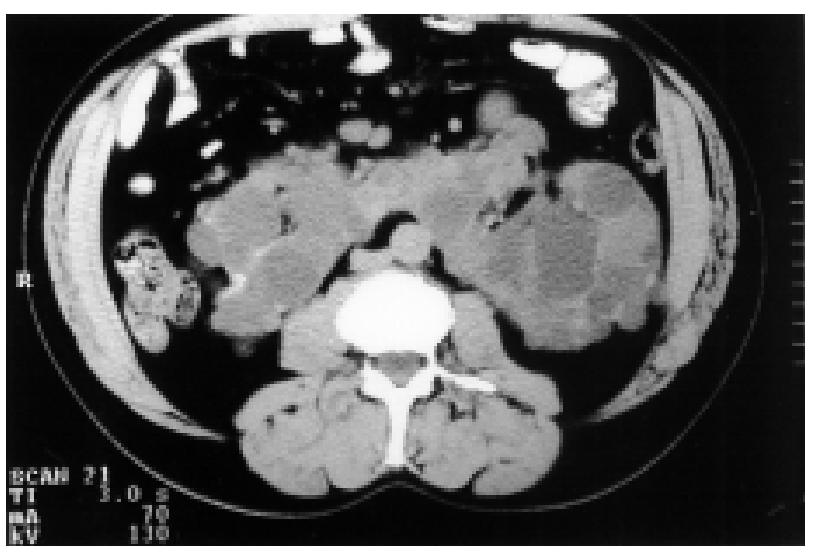

FIGURA 1. TAC abdominal del paciente.

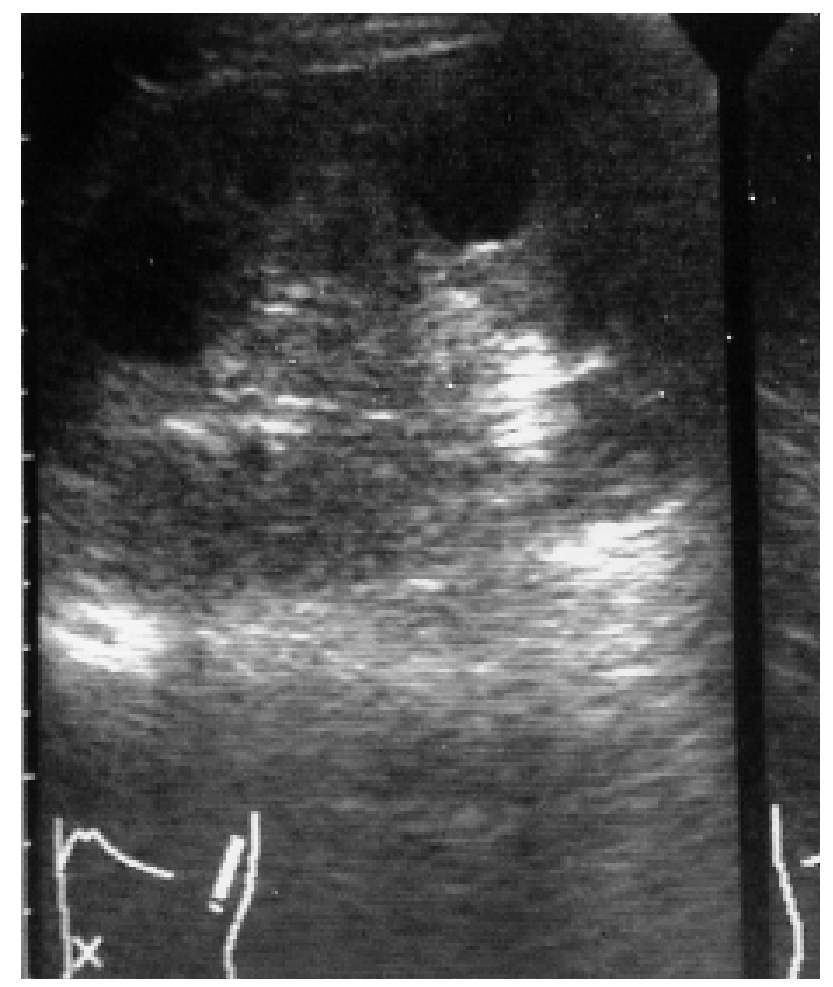

FIGURA 2. Ecografia abdominal del hijo varón.

La asociación de ambas entidades, según se desprende de lo comentado, es bastante inusual, con rangos de incidencia que van desde $1 / 134000$ hasta $1 / 8$ millones de casos, habiéndose descrito hasta 1997 menos de 20 casos en la literatura ${ }^{2}$.

El manejo terapéutico de estos casos está basado eminentemente en el control de las manifestaciones clínicas propias de la insuficiencia renal que presentan estos pacientes.

\section{REFERENCIAS}

1. CAGLAR K, KIBAR Y, TAHMAZ L, TEKIN A, YENICESU M, VURAL A.: Polycystic horseshoe kidney. Clin Nephrol 2001 jun; 55 (6): 487-488.

2. BRUMM FA, BECKER M, UGLIONE A, DA ROS CT.: Polycystic horseshoe kidney. J Urol 1997 dec; 158 (6): 2229-2230.

3. CORREA RJ Jr, PATON RR.: Polycystic horseshoe kidney. J Urol 1976 dec; 116 (6): 802.

4. HARRIS J, ROBERT E, CALLEN B.: Epidemiologic characteristics of kidney malformations. Eur J Epid 2000; 200 (16): 985-992.

Dr. R. Ferrero Doria

Avda. Albaida, 2 - Esc. 2, pta. 18

46870 Onteniente (Valencia)

(Trabajo recibido el 19 mayo de 2003) 